\title{
Development of weight and age-based dosing of daily primaquine for radical cure of vivax malaria
}

\author{
Walter Robert Taylor ${ }^{1,2^{*}}$, Richard M. Hoglund ${ }^{1,2}$, Pimnara Peerawaranun ${ }^{1}$, Thuy Nhien Nguyen ${ }^{3}$, \\ Tran Tinh Hien 2,3, Arnaud Tarantola ${ }^{4}$, Lorenz von Seidlein ${ }^{1,2}$, Rupam Tripura 1,2,5, Thomas J. Peto ${ }^{1,2}$, \\ Arjen M. Dondorp ${ }^{1,2}$, Jordi Landier ${ }^{6,7}$, Francois H.Nosten ${ }^{2,6}$, Frank Smithuis ${ }^{8}$, Koukeo Phommasone ${ }^{9,10}$, \\ Mayfong Mayxay ${ }^{9,11}$, Soy Ty Kheang ${ }^{12,13}$, Chy Say ${ }^{12}$, Kak Neeraj ${ }^{14}$, Leang Rithea ${ }^{15}$, Lek Dysoley ${ }^{15,16}$, Sim Kheng ${ }^{15}$, \\ Sinoun Muth ${ }^{15}$, Arantxa Roca-Feltrer ${ }^{17}$, Mark Debackere ${ }^{18}$, Rick M. Fairhurst ${ }^{19}$, Ngak Song ${ }^{20}$, Philippe Buchy ${ }^{4,21}$, \\ Didier Menard $^{4,22}$, Nicholas J. White ${ }^{1,2}$, Joel Tarning ${ }^{1,2+}$ and Mavuto Mukaka ${ }^{1,2 \dagger}$
}

\begin{abstract}
Background: In many endemic areas, Plasmodium vivax malaria is predominantly a disease of young adults and children. International recommendations for radical cure recommend fixed target doses of $0.25 \mathrm{or} 0.5 \mathrm{mg} / \mathrm{kg} /$ day of primaquine for 14 days in glucose-6-phosphate dehydrogenase normal patients of all ages. However, for many antimalarial drugs, including primaquine, there is evidence that children have lower exposures than adults for the same weight-adjusted dose. The aim of the study was to develop 14-day weight-based and age-based primaquine regimens against high-frequency relapsing tropical P. vivax.
\end{abstract}

Methods: The recommended adult target dose of $0.5 \mathrm{mg} / \mathrm{kg} / \mathrm{day}$ (30 mg in a $60 \mathrm{~kg}$ patient) is highly efficacious against tropical P. vivax and was assumed to produce optimal drug exposure. Primaquine doses were calculated using allometric scaling to derive a weight-based primaquine regimen over a weight range from 5 to $100 \mathrm{~kg}$. Growth curves were constructed from an anthropometric database of 53,467 individuals from the Greater Mekong Subregion (GMS) to define weight-for-age relationships. The median age associated with each weight was used to derive an age-based dosing regimen from the weight-based regimen.

Results: The proposed weight-based regimen has 5 dosing bands: (i) $5-7 \mathrm{~kg}, 5 \mathrm{mg}$, resulting in $0.71-1.0 \mathrm{mg} / \mathrm{kg} /$ day; (ii) 8-16 kg, 7.5 mg, 0.47-0.94 mg/kg/day; (iii) $17-40$ kg, 15 mg, 0.38-0.88 mg/kg/day; (iv) $41-80$ kg, 30 mg, $0.37-0.73 \mathrm{mg} / \mathrm{kg} /$ day; and (v) $81-100 \mathrm{~kg}, 45 \mathrm{mg}, 0.45-0.56 \mathrm{mg} / \mathrm{kg} /$ day. The corresponding age-based regimen had 4 dosing bands: $6-11$ months, 5 mg, $0.43-1.0 \mathrm{mg} / \mathrm{kg} /$ day; (ii) $1-5$ years, $7.5 \mathrm{mg}, 0.35-1.25 \mathrm{mg} / \mathrm{kg} / \mathrm{day}$; (iii) 6-14 years, $15 \mathrm{mg}, 0.30-1.36 \mathrm{mg} / \mathrm{kg} /$ day; and (iv) $\geq 15$ years, $30 \mathrm{mg}, 0.35-1.07 \mathrm{mg} / \mathrm{kg} /$ day.

Conclusion: The proposed weight-based regimen showed less variability around the primaquine dose within each dosing band compared to the age-based regimen and is preferred. Increased dose accuracy could be achieved by

\footnotetext{
*Correspondence: bob@tropmedres.ac

†Joel Tarning and Mavuto Mukaka contributed equally to this work

${ }^{1}$ Mahidol Oxford Tropical Medicine Research Unit, Faculty of Tropical

Medicine, Mahidol University, 420/60 Rajvithi Road, Bangkok 10400,

Thailand

Full list of author information is available at the end of the article
}

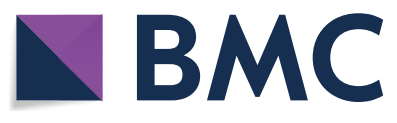

(c) The Author(s) 2021. Open Access This article is licensed under a Creative Commons Attribution 4.0 International License, which permits use, sharing, adaptation, distribution and reproduction in any medium or format, as long as you give appropriate credit to the original author(s) and the source, provide a link to the Creative Commons licence, and indicate if changes were made. The images or other third party material in this article are included in the article's Creative Commons licence, unless indicated otherwise in a credit line to the material. If material is not included in the article's Creative Commons licence and your intended use is not permitted by statutory regulation or exceeds the permitted use, you will need to obtain permission directly from the copyright holder. To view a copy of this licence, visit http://creativecommons.org/licenses/by/4.0/. The Creative Commons Public Domain Dedication waiver (http://creativeco mmons.org/publicdomain/zero/1.0/) applies to the data made available in this article, unless otherwise stated in a credit line to the data. 
additional dosing bands for both regimens. The age-based regimen might not be applicable to regions outside the GMS, which must be based on local anthropometric data. Pharmacokinetic data in small children are needed urgently to inform the proposed regimens.

Keywords: Primaquine, Allometric scaling, Age-based dosing, Weight-based dosing, Plasmodium vivax

\section{Background}

Primaquine and tafenoquine are the only registered drugs recommended currently to kill Plasmodium vivax and Plasmodium ovale hypnozoites (dormant parasites residing in the liver) and prevent relapses, which are fresh blood-stage infections that arise periodically from hypnozoites. Although primaquine has been available since the 1950s, there are no internationally recommended practical regimens that detail the dose to be given for a given weight band in patients with normal (G6PDn) or deficient (G6PDd) glucose-6-phosphate dehydrogenase activity.

The World Health Organization (WHO) recommends $0.5 \mathrm{mg} / \mathrm{kg} /$ day for 14 days (total dose of $7.0 \mathrm{mg} / \mathrm{kg}$ ) for South East Asia and Oceania and $0.25 \mathrm{mg} / \mathrm{kg} /$ day for 14 days (total dose of $3.5 \mathrm{mg} / \mathrm{kg}$ ) elsewhere [1, 2]. Weekly primaquine at $0.75 \mathrm{mg} / \mathrm{kg}$ for 8 weeks is recommended for G6PDd patients in all regions. In the absence of established dosing regimens, researchers and malaria control programmes (MCPs) have used many different weightand age-based regimens, adapting the recommended weight-based target doses to their populations [3] (Additional file 1: Table S1). Complex regimens with multiple dosing bands (20 and 21 in two trials $12[4,5]$ ) result in more accurate dosing but are too cumbersome to administer outside of the research setting. Different primaquine regimens might result in under- or over dosing in particular patient groups so an evidence-based approach is essential to develop primaquine regimens.

Moreover, getting the dose right is crucial because the antirelapse efficacy of primaquine depends on the total exposure to primaquine $[6,7]$. However, fixed weight-based target doses across ages often results in underexposure in small children due to their greater weight-normalised clearance $(\mathrm{L} / \mathrm{h} / \mathrm{kg})$ compared to older children and adults. This results in a nonlinear relationship between drug exposure and body weight at a specific weight-based target dose [8]. Limited data on single low dose primaquine (SLDPQ), dosed at 0.25 or $0.4 \mathrm{mg} /$ $\mathrm{kg}$, administered on Day 2 in artemether-lumefantrine treated Plasmodium falciparum-infected African children aged 2-14 years, showed that primaquine and carboxyprimaquine exposures were lower in young children (i.e. low body weight) [9]. Based on their pharmacokinetic model, Goncalves et al. predicted approximately half the peak primaquine concentrations in a 2 -year old child (12 kg) compared to a 14-year old child (40 kg) after receiving $0.25 \mathrm{mg} / \mathrm{kg}$ of primaquine $(\sim 30 \mathrm{ng} / \mathrm{mL}$ vs. $\sim 73 \mathrm{ng} / \mathrm{mL}$ and showed increasing exposure to primaquine and carboxyprimaquine with increasing weight and age. The lack of pharmacokinetic data in young children with vivax malaria is a major evidence gap. If the trends to lower exposures at younger age observed in African children given SLDPQ are confirmed then dose regimens based largely on adult data will need to be revised.

Dosing by age is intrinsically less accurate than dosing by body weight because of the high degree of variability of bodyweight for a given age, but it has the advantage of not requiring weighing scales, which is desirable in mass drug administrations, the informal health system and remote areas [10-12]. The aim of primaquine therapy is to achieve high efficacy and good tolerability within acceptable therapeutic ranges, irrespective of the dosing strategy (age vs. bodyweight dosing).

There is good evidence, mostly in adults, of the high efficacy of radical cure primaquine against tropical $P$. vivax with a total target dose of $7 \mathrm{mg} / \mathrm{kg}[4,5,13,14]$ and a fall in efficacy with lower doses [15-17]. Modest antirelapse efficacy of $58 \%$, relative to no primaquine, was reported for the $7 \mathrm{mg} / \mathrm{kg}$ regimen in children aged 1-5 years from Papua New Guinea [18], a high risk group for relapse [19]. There are insufficient data to define a minimally effective total dose in children $<5$ years but in adults and likely in children aged $\geq 5$ years [20], this is probably $\sim 5.25 \mathrm{mg} / \mathrm{kg}$. This dose resulted in relapse rates of $0 \%, \sim 2 \%$ and $\sim 7 \%$ in volunteers with experimentallyinduced Chesson strain of $P$. vivax [17], in Thai patients [21], and in Australian soldiers [22], respectively. By contrast, the $3.5 \mathrm{mg} / \mathrm{kg}$ total dose, which is recommended by some GMS countries, was associated with variable relapse rates ranging from $\sim 7$ to $25 \%$ [21, 23-25] and was $50 \%$ in adults with Papuan-acquired P. vivax (K. Baird, pers. commun.).

Abdominal pain, methaemoglobinaemia and acute haemolysis in G6PD deficient individuals are dosedependent primaquine toxicities but G6PD status per se does not affect primaquine pharmacokinetics [26]. Abdominal pain is reduced by food [27, 28], which also increases primaquine exposure [29]. Rates of abdominal pain in the IMPROV study (median age of 16 years) were significantly higher in the 1.0 vs. $0.5 \mathrm{mg} / \mathrm{kg} /$ 
day $\operatorname{arm}(43 \%$ vs. $34 \%, \mathrm{p}<0.0001)$ and placebo $(29 \%$, $\mathrm{p}<0.0001$ ), while rates of early vomiting were remarkably low ( $2 \%$ in all three arms) and only $5 / 935(0.53 \%)$ of $1.0 \mathrm{mg} / \mathrm{kg}$ recipients stopped primaquine temporarily because of gastrointestinal toxicity [4]. Similarly, $\mathrm{Chu}$ et al. reported rates of abdominal pain of $33 \%$ vs. $27 \%$ and $20 \%$ vs. $10 \%$ ( 1.0 vs. $0.5 \mathrm{mg} / \mathrm{kg} /$ day) in chloroquine and dihydroartemisinin-piperaquine recipients (median age of 20 years), respectively. No patients stopped their primaquine early [5]. In both studies, children $<5$ years represented only $4 \%$ [5] and $6 \%$ [4] of patients.

Methaemoglobinaemia varies considerably between individuals and is well tolerated in healthy individuals and malaria patients even when receiving the $1.0 \mathrm{mg} / \mathrm{kg}$ dose $[5,30,31]$. The median methaemoglobinaemia was $7.5 \%$ in the $1.0 \mathrm{mg} / \mathrm{kg} /$ day arm with $4 / 327$ (1.2\%) stopping their primaquine early [5]. Clinically significant, primaquine-induced haemolysis is greater in G6PD deficient hemizygous males and homozygous females compared to G6PD heterozygous females [32]. In Thailand, G6PDd heterozygous females receiving $1.0 \mathrm{mg} / \mathrm{kg} /$ day of primaquine had a greater mean fractional fall in haematocrit vs. those receiving $0.5 \mathrm{mg} / \mathrm{kg} / \mathrm{day}$ ( 23.6 vs. $15.5 \%$, $\mathrm{p}=0.001$ ) and two females in the former group were transfused [33]. Taken together, these data demonstrate the better tolerability of the $0.5 \mathrm{mg} /$ day dose, but are insufficient to define with confidence a maximally tolerated dose.

Following a request from a malaria control programme for a practical dosing regimen of primaquine for radical cure, it was decided to develop a weight-based regimen and explore the possibility of an age-based regimen.

\section{Methods}

\section{Anthropometric data}

An anthropometric database was assembled, using data provided by researchers (malaria patients, clinic data), and the Demographic Health Survey (DHS), collected from large household, nationally representative survey data of mostly healthy individuals, from GMS countries $(\mathrm{n}=54,660)$. As done previously [34, 35], a waiver for ethical review was granted by the Oxford Tropical Ethics Committee for analysing these anonymized data.

The raw weight-for-age data were modelled into growth curves (Fig. 1 \& Additional file 2: Figures S1 \& S2) to define the relationship between weight and age [36] using a three-parameter Box-Cox power exponential distribution [37] and cubic spline smoothing [38]. Outliers were excluded from the database by removing data outside the $1^{\text {st }}$ and $99^{\text {th }}$ percentiles $(\mathrm{n}=1193)$, resulting in a total number of 53,467 patients in the final database.

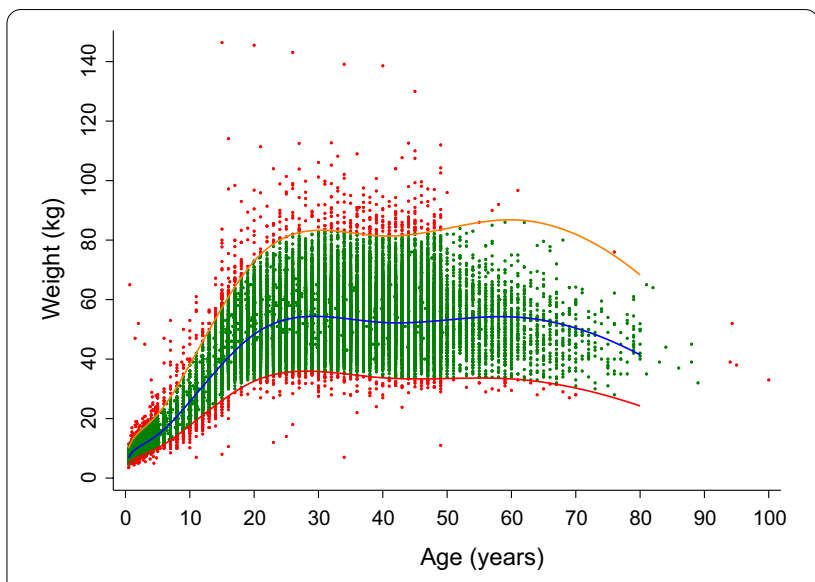

Fig. 1 Distribution of the individual anthropometric weight-for-age data in the Greater Mekong Subregion for both sexes combined. The blue line represents the median when applying a three-parameter Box-Cox power exponential distribution and cubic spline smoothing, while the red and orange lines represent the 1st and 99th percentiles, respectively, of the model. The pink markers show outliers outside the $98 \%$ prediction interval of the model $(n=1193)$, and the green markers represent the observed data retained in the final model $(n=53,467)$

\section{Weight-based dosing regimen}

Consistent with WHO recommendations and the strong evidence base for high efficacy of the $0.5 \mathrm{mg} / \mathrm{kg}$ daily dose in tropical $P$. vivax, the primaquine target dose was set to $0.5 \mathrm{mg} / \mathrm{kg} /$ day (i.e. $30 \mathrm{mg}$ in a $60 \mathrm{~kg}$ patient, resulting in the target primaquine exposure). A theoretical dose for each bodyweight was calculated using allometric scaling (Eq. 1) with the aim of achieving comparable drug exposure in all patients.

$$
\text { Theoretical dose }(\mathrm{mg})=30 \mathrm{mg} \times\left(\frac{\mathrm{BW}}{60 \mathrm{~kg}}\right)^{0.75}
$$

$\mathrm{BW}$ is the individual body weight $(\mathrm{kg})$ and $30 \mathrm{mg}$ is the optimal dose in a $60 \mathrm{~kg}$ patient. Five primaquine doses were chosen (i.e. 5, 7.5, 15, 30, and $45 \mathrm{mg}$ ) to develop a programmatically feasible primaquine regimen with the current dosing strengths.

Each body weight was assigned to the dose that minimized the residuals between the calculated theoretical dose and the chosen dose. The fifth dosing band (i.e. $45 \mathrm{mg}$ ) was added specifically to address under-dosing in heavier patients $(>80 \mathrm{~kg})$.

\section{Age-based dosing}

The observed weight-for-age data in the final data base was used to calculate the median age for each body weight (1 $\mathrm{kg}$ increments). The age-based dosing was developed by replacing the weight bins in the 
weight-based regimen with the median age for each weight. Thus, it was not possible to separate heavier adults (>80 kg) from standard-weight adults $(41-80 \mathrm{~kg})$ in the age-based dosing. This resulted in a total of four age-based dosing bands. The predicted $\mathrm{mg} / \mathrm{kg}$ dose for each age was then calculated.

\section{Pharmacokinetic simulations}

Simulations of primaquine and carboxyprimaquine exposures were carried out using a previously published pharmacokinetic model [39] and a simulation dataset. In the pharmacokinetic model, drug absorption was characterized by five-transit absorption compartments, with pre-systemic metabolism of primaquine to carboxyprimaquine. Primaquine and carboxyprimaquine were characterised by one-compartment disposition models. The model included allometrically-scaled body weight as a covariate with the exponents fixed to 0.75 for clearance parameters and 1 for volume parameters. These scaling exponents were used also in two previously published primaquine studies $[9,20]$. Furthermore, the 0.75 exponent is used widely in paediatric dosing to compensate for the increased total drug clearance/unit weight in children, which commonly peaks at age 2 and is followed by a slow exponential decline [40, 41].

The model did not adjust for CYP2D6 metabolic status or use an enzymatic maturation factor to compensate for age-dependent drug clearance in very young children. CYP2D6-related poor metabolic activity is associated with poor primaquine efficacy $[42,43]$ and has a low prevalence rate $(\sim 1-9 \%)$ in South East Asia, contrasting with the high rates $(40-60 \%)$ of the *10 genotype, which confers intermediate primaquine metabolism [44-46]. Given the high efficacy rates of the $0.5 \mathrm{mg} / \mathrm{kg} /$ day dose in tropical P. vivax in South East Asia, the effect of intermediate primaquine metabolic status appears small. A maturation factor for clearance is advocated by some authorities to take into account the immaturity of metabolizing enzymes and reduced renal function, seen mostly in neonates and infants $[8,47]$. However, maturation of the clearance function was not included in the original published model [39] and more data would be needed to confirm the pharmacokinetic properties of primaquine in neonates and infants.

A simulation dataset was constructed from the observed anthropometric weight-for-age data $(\mathrm{n}=54,660)$ by excluding pregnant women, patients above 50 years of age, and patients weighing $<5 \mathrm{~kg}$ and $>100 \mathrm{~kg}$. The data in pregnant women were excluded as the model was not developed for this population and the relationship between age and weight might be different in this group. The limitation in weight and age was due to the limited amount of data outside the included intervals (5-100 kg and 0-50 years), which could make simulations in these groups of patients uncertain and unreliable. The data were then divided into $1 \mathrm{~kg}$ bins, and the data below the 1st and above the 99th percentile was removed from each bin, resulting in a simulation dataset of 50,872 individuals.

The developed weight-based and age-based dosing regimens were used to simulate a total of 1000 single dose exposures of primaquine in each of the 50,872 individual patients in the simulation dataset (i.e. a total of 50,872,000 simulated patients in each dose regimen) in NONMEM v7.3 (Icon Development Solutions, Ellicott City, Maryland, USA). Exposure up to $60 \mathrm{~h}$ post-dose was calculated based on these simulations, and visualised as the 2.5th, 50th and 97.5th percentiles, using $\mathrm{R}$ v4.0.0 (the $R$ Foundation for Statistical Computing, Vienna, Austria).

\section{Results}

\section{Database description}

The modelled weight-for-age database contained 53,467 individuals with a median age and weight of 23 years (IQR 9-35) and 46.3 kg (IQR 21.5-54.1 kg). Females $(36,733 / 53,467,68.7 \%)$ outnumbered males and most individuals were healthy $(86.0 \%, 45,949 / 53,467)$; $6244 / 53,467$ (11.7\%) had malaria (Table 1). Median weights were similar in males and females for all age groups, but with a greater difference in older individuals aged $\geq 15$ years (males weighing a median of $3.4 \mathrm{~kg}$ more than females). Median weights were also similar between healthy individuals and those with malaria or other infections (Table 2 and Additional file 3: Figure S3).

The relationship between weight and age was described by a three parameter model, denoted by Box-Cox power exponential distribution $(\theta, \delta, \lambda)$ where $\theta$ is the median, $\delta$ is the scale parameter, and $\lambda$ is the skewness parameter. We obtained The following parameter estimates were obtained after fitting the model; $\widehat{\theta}=40.3$ (95\% CI $40.2-$ 40.5); $\widehat{\delta}=0.1707$ (95\% CI $0.1706-0.1708) ; \widehat{\lambda}=-0.183$. The $\lambda$ (skewness parameter) is a constant and, therefore, no corresponding confidence interval can be estimated.

\section{Allometrically scaled weight-based regimen}

The proposed regimen has five dosing bands, covering weights from 5 to $100 \mathrm{~kg}$ (Table 2). Simulated primaquine exposures, after applying the proposed weight-based dosing, resulted in evenly distributed exposures around the target exposure (Fig. 2), with a maximum of a 2.85fold difference between the lowest and highest exposure (i.e. 2.5-97.5 percentile of simulated exposures) within a body weight (Fig. 3). The predicted median primaquine exposure $\left(\mathrm{AUC}_{0-60}\right)$ in a $60 \mathrm{~kg}$ individual was approximately $1200 \mathrm{~h} \times \mathrm{ng} / \mathrm{mL}$. 
Table 1 Summary of anthropometric weight-for-age data in the Greater Mekong Subregion

\begin{tabular}{llll}
\hline Characteristics, $\mathbf{n}(\mathbf{\%})$ & Total $^{\mathbf{a}}(\mathbf{N}=\mathbf{5 3 , 4 6 7 )}$ & Male $(\mathbf{n}=\mathbf{1 6 , 3 8 8})$ & Female $(\mathbf{n}=\mathbf{3 6 , 7 3 3 )}$ \\
\hline Country & & & $19,189(52.2)$ \\
Cambodia & $29,867(55.9)$ & $10,334(63.1)$ & $15,460(42.1)$ \\
Myanmar & $18,577(34.7)$ & $3117(19.0)$ & $1303(3.6)$ \\
Vietnam & $3412(6.4)$ & $2107(12.9)$ & $781(2.1)$ \\
Laos & $1611(3.0)$ & $830(5.1)$ & $26(16-37)$ \\
Age groups (years), median (IQR) & $23(9-35)$ & $14(4-28)$ & {$[0.5-89]$} \\
[range] & {$[0.5-89]$} & {$[0.5-83]$} & $526(1.4)$ \\
$<1^{b}$ & $1063(2.0)$ & $537(3.3)$ & $5027(13.7)$ \\
$1-5$ & $10,296(19.3)$ & $5256(32.1)$ & $2187(6.0)$ \\
$6-14$ & $4722(8.8)$ & $2503(15.3)$ & $28,993(78.9)$ \\
$\geq 15$ & $37,386(69.9)$ & $8092(49.4)$ & $47.2(39.0-54.5)$ \\
Weight (kg), median (IQR) [range] & $46.3(21.5-54.1)$ & $36.0(13.2-53.0)$ & {$[5.0-82.9]$} \\
& {$[5.0-86.0]$} & {$[5.1-86.0]$} & $1086(3.0)$ \\
$>70$ kg & $1320(2.5)$ & $229(1.4)$ & $428(1.2)$ \\
Health status & $499(0.9)$ & $69(0.4)$ & $34,941(95.1)$ \\
Healthy & & & $1245(3.4)$ \\
Malaria & $45,949(86.0)$ & $10,988(67.1)$ & $546(1.5)$ \\
Other infections & $6244(11.7)$ & $4981(30.4)$ & $0(0.0)$ \\
No diagnosis & $1247(2.3)$ & $393(2.4)$ & $13(0.1)$ \\
\hline
\end{tabular}

a Sex at birth undocumented in 346 individuals

${ }^{\mathrm{b}}$ Age 6 to 11 months

Table 2 Weight as a function of sex and disease status

\begin{tabular}{lccc}
\hline Age groups (years) & Total N & \multicolumn{2}{l}{ Weight (kg), median (IQR) } \\
\cline { 3 - 4 } & Male-female & Male & Female \\
\hline$<1^{\text {a }}$ & $1063(537-526)$ & $8(7.3-8.6)$ & $7.5(6.9-8)$ \\
$1-5$ & $10,283(5256-5027)$ & $12(10.2-13.9)$ & $11.5(9.9-13.2)$ \\
$6-14$ & $4690(2503-2187)$ & $23(19-29)$ & $23(18-30)$ \\
$\geq 15$ & $37,085(8092-28,993)$ & $53.4(49-59)$ & $50(45-56.6)$ \\
\hline & Healthy-malaria ${ }^{\mathbf{b}}$ & Healthy & Malaria \\
\hline 1 & $1063(1037-26)$ & $7.7(7-8.4)$ & $7.7(7-8)$ \\
$6-14$ & $10,295(9613-682)$ & $11.9(10-13.6)$ & $11.5(10-13)$ \\
$\geq 15$ & $4721(3195-1526)$ & $23(18.1-29)$ & $24(19-30)$ \\
\hline
\end{tabular}

age 6 to 11 months

${ }^{\mathrm{b}}$ Malaria and miscellaneous infections

\section{Age-based dosing regimen}

The proposed age-based regimen has four dosing bands starting at 6 months of age (Table 3); the resulting $\mathrm{mg} /$ $\mathrm{kg}$ dose for each age is shown in Additional file 4: Figure S4 and Additional file 5: Table S2. Patients aged 15 years were predicted to receive low doses if assigned $15 \mathrm{mg}$ (median of $0.34 \mathrm{mg} / \mathrm{kg}$ ) compared to $30 \mathrm{mg}$ (median of $0.68 \mathrm{mg} / \mathrm{kg}$ ); therefore, they were allocated
$30 \mathrm{mg}$ of primaquine. Simulated primaquine exposures, after applying the proposed age-based dosing, resulted in a substantially higher variability around the target exposure compared to the weight-based dosing (Figs. 2 and 3). A maximum of a 4.79-fold difference was seen between the lowest and highest exposure (i.e. 2.5-97.5 percentile of simulated exposures) within a bodyweight (Fig. 3). 

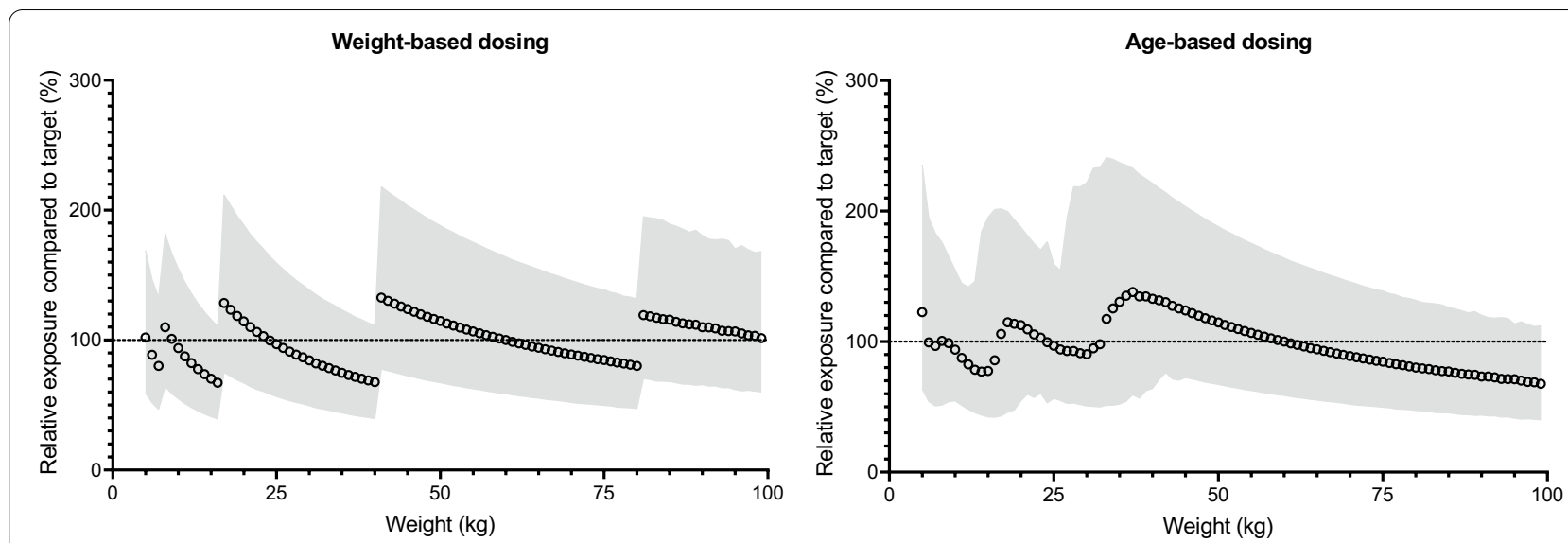

Fig. 2 Simulated primaquine exposures, relative to the median exposure following administration of $30 \mathrm{mg}$ primaquine base in a $60 \mathrm{~kg}$ patient (i.e. target exposure) for the developed weight-based and age-based dosing regimens. The shaded areas represent the 2.5th and 97.5 th percentiles of the simulated exposures

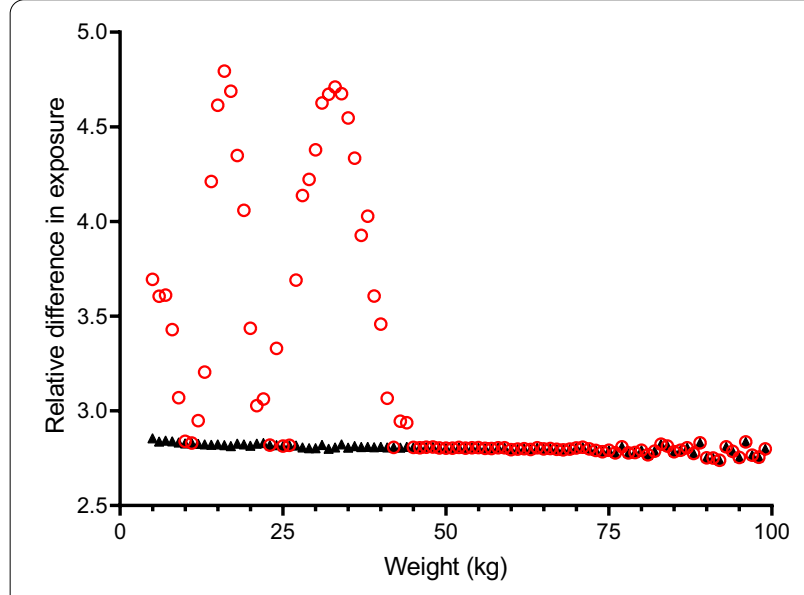

Fig. 3 Relative variability in simulated exposure after different dosing regimens. Markers illustrate the relative difference between the simulated 2.5th and 97.5 th percentiles of primaquine exposure, stratified on bodyweight. Variability associated with bodyweight-based dosing is shown as black triangles and variability associated with age-based dosing is shown as red circles

\section{Discussion}

This analysis has shown that a weight-based regimen can be designed within the parameters set by a MCP in the GMS, using available tablet strengths and designing dosing bands to avoid tablet fractions. Although the GMS population is generally slender, a fifth weight-based dosing band was essential to avoid under-dosing and low efficacy in heavier patients [7, 22, 48]. A 4-band, age-based regimen was successfully derived from the weight-based regimen but, as expected, resulted in greater variability in expected exposures and would be considered suitable only if weight-based dosing cannot be implemented.

MCPs, striving to eliminate $P$. vivax malaria, need tolerable, effective and user-friendly regimens. Only primaquine or tafenoquine are available to be deployed currently but both require G6PD testing before use and tafenoquine cannot be given to patients with $<70 \%$ G6PD enzyme activity. This will exclude a substantial number of patients, especially G6PD deficient heterozygous women [49]. Thus, there is still an urgent need to develop an

Table 3 Proposed weight-based and age-based dosing of primaquine

\begin{tabular}{|c|c|c|c|c|c|}
\hline \multicolumn{3}{|c|}{ Weight-based dosing } & \multicolumn{3}{|c|}{ Age-based dosing } \\
\hline Bodyweight (kg) & $\begin{array}{l}\text { Primaquine daily } \\
\text { dose }^{a}(\mathrm{mg})\end{array}$ & $\begin{array}{l}\text { Primaquine daily dose }{ }^{a} \\
\text { (mg/kg/day) }\end{array}$ & Age (years) & $\begin{array}{l}\text { Primaquine daily } \\
\text { dose }^{a}(\mathrm{mg})\end{array}$ & $\begin{array}{l}\text { Primaquine daily } \\
\text { dose }{ }^{\mathrm{a}}(\mathrm{mg} / \mathrm{kg} / \\
\text { day) }\end{array}$ \\
\hline $5-7$ & 5 & $0.71-1.00$ & $<1^{\mathrm{b}}$ & 5 & $0.43-1.00$ \\
\hline $8-16$ & 7.5 & $0.47-0.94$ & $1-5$ & 7.5 & $0.34-1.25$ \\
\hline $17-40$ & 15 & $0.38-0.88$ & $6-14$ & 15 & $0.28-1.30$ \\
\hline $41-80$ & 30 & $0.37-0.73$ & $\geq 15$ & 30 & $0.35-1.11$ \\
\hline $81-100$ & 45 & $0.45-0.56$ & & & \\
\hline
\end{tabular}

a Daily dose based on a 14-day regimen

${ }^{b}$ The lowest age-band is proposed for infants is 6 months to 11 months of age 
optimized dosing regimen of primaquine for programme deployment.

Primaquine has several challenges, including adherence to 14-day [19, 50] and even 7-day regimens [51]. The limited availability of tablet strengths that are made according to international good manufacturing practice, 7.5 and $15 \mathrm{mg}$, leads to inaccurate, impractical regimens necessitating tablet fractions. Owing to the paucity of pharmacokinetic data, especially in malaria-infected children, who experience reduced drug exposure $[3,9]$, there are no WHO-approved, evidenced-based, allometricallyscaled, weight-based dosing regimens for radical cure.

Therefore, the aim of this study was to design such a dosing regimen using a detailed, published, structural pharmacokinetic model based on adult data [39]. The predicted total, primaquine exposure from this model was $1200 \mathrm{~h} \times \mathrm{ng} / \mathrm{mL}$ after $30 \mathrm{mg}$ of primaquine in a $60 \mathrm{~kg}$ patient (the predefined optimal dose), consistent with the value of $521 \mathrm{~h} \times \mathrm{ng} / \mathrm{mL}$ obtained from $15 \mathrm{mg}$ in Thai patients [26] and $610 \mathrm{~h} \times \mathrm{ng} / \mathrm{mL}$ predicted from a pharmacokinetic model of healthy, non-obese Korean adults given $15 \mathrm{mg}$ of primaquine with hydroxychloroquine [52]. Moreover, the allometrically-scaled, weight-based regimen predicted similar primaquine exposures across all weight groups with a $<3$-fold difference in exposure.

Goncalves et al. reported that their allometricallyscaled pharmacokinetic model overestimated primaquine and carboxyprimaquine exposures in their falciparuminfected children, before implementing an age-related covariate on the relative bioavailability of primaquine (i.e. accounting for increased relative bioavailability with increasing age). Their model also showed increasing primaquine and carboxyprimaquine exposure with decreasing CYP2D6 metabolic activity.

The model used in the simulations reported here did not include an enzymic maturation factor, nutritional or CYP2D6 metabolizer status. The inclusion of an enzymatic maturation factor in the current pharmacokinetic model could lead to higher primaquine exposure in very young children $(<2$ years) than predicted from the simulations. This should have no effect on the efficacy of primaquine in this group, but might need to be considered in terms of safety. Further studies are needed to fully characterize the effect of enzyme maturation on primaquine pharmacokinetics before this can be taken into consideration for this group of patients.

Another factor that could affect the dose regimen is severe acute malnutrition, which has been shown to reduce lumefantrine exposure [53]. How nutritional status affects primaquine pharmacokinetics and whether the proposed dosing would be optimal for this sub-group of patients are unclear. However, the omission of malnutrition and CYP2D6 metabolizer status is no different from current dosing, and the proposed dosing regimen suggested here will not augment these limitations.

Restricting the number of dosing bands resulted in broad weight bands of $17-40 \mathrm{~kg}$ and $41-80 \mathrm{~kg}$, and a relatively low total dose of $5.25 \mathrm{mg} / \mathrm{kg}$ as well as high $\mathrm{mg} / \mathrm{kg}$ dose that increased with decreasing age. Unlike previous work on SLDPQ [34, 35, 54], 'optimal' therapeutic dosing ranges of daily primaquine for different weight/age bands were not defined because of the paucity of efficacy, safety and pharmacokinetic data in children $<5$ years, the differential risk of primaquine-induced haemolysis by G6PD status, and the risk benefit ratio once reliable field-adapted G6PD tests become available. Nevertheless, limited evidence, chiefly in adults, supports a total dose of $5.25 \mathrm{mg} / \mathrm{kg}$ as the minimum effective dose [17, 21, 22] and a probable maximum tolerated dose of $1 \mathrm{mg} / \mathrm{kg} / \mathrm{day}$, given its risks of blood transfusion in G6PD heterozygous females with South East Asian G6PD variants [33] and high rates of abdominal pain $[4,5,27,28]$.

The proposed dosing could be optimized further by using more dosing bands for both weight-based and age-based regimens, while still using the same tablet strengths, but they might be less user-friendly for patients and health workers. Accordingly, the needs of MCPs should be expressed clearly and channelled through the WHO so a consensus on dosing can be reached to put an end to the multiplicity of regimens and the vagueness of a simple $\mathrm{mg} / \mathrm{kg}$ target dose.

The study reported herein has several limitations. Firstly, the weight-based regimen presented is based on a model that was constructed using adult pharmacokinetic data, which was adjusted for body weight but not for CYP2D6 status or maturation of physiological processes that might affect the pharmacokinetic properties. Although the anthropometric database was large, $70 \%$ of subjects were female and a fifth were children $<5$ years, because the predominance of the DHS data; in addition, the total number of heavy individuals was small. Extending DHA data collection to include older children of both sexes would be a helpful step. Our database was from the GMS; therefore, the age-based dosing regimen cannot be generalized to other regions because anthropometric characteristics vary by region [55]. Finally, dosing based on body surface area was not considered but this approach is currently not realistic in most malaria endemic settings where 8 -aminoquinoline regimes are used.

\section{Conclusions}

Work presented here proposes a weight-based and an age-based dosing radical cure regimen of primaquine for tropical $P$. vivax, using tablet strengths called for by the $\mathrm{WHO}$ and already proposed in regimens of SLDPQ. 
The age-based dosing showed substantially more variability in expected exposures and should be used only if weight-based dosing cannot be implemented. Young children bear the brunt of the $P$. vivax burden in endemic areas as they have relatively little disease controlling immunity. Relapses are frequent and associated with significant morbidity. These dose recommendations for primaquine radical cure based largely on adult data should be regarded as provisional pending further information on the pharmacokinetic properties of primaquine in younger children. If the trends observed in African children given SLDPQ are confirmed in young children receiving radical curative regimens for vivax malaria, and there is evidence for correspondingly reduced bioactivation of primaquine, then doses will need to be increased.

\section{Abbreviations}

CYP: Cytochrome; DHS: Demographic Health Survey; G6PDd: Glucose6-phosphate dehydrogenase deficiency; GMS: Greater Mekong Sub Region; IMPROV: Improving the Radical Cure of Vivax Malaria; $n$ : Normal; MCP: Malaria Control Programme; SLDPQ: Single low dose primaquine; WHO: World Health Organization.

\section{Supplementary Information}

The online version contains supplementary material available at https://doi. org/10.1186/s12936-021-03886-w.

Additional file 1: Table S1. Primaquine regimens for radical cure of P. vivax malaria used in studies and recommended by malaria control programs.

Additional file 2: Figure S1 \& S2. Weight-for-age growth curves for the Greater Mekong Subregion up to 60 and 15 years of age.

Additional file 3: Figure S3. Weight distributions, stratified by sex and disease status in the four age categories.

Additional file 4: Figure S4. The $\mathrm{mg} / \mathrm{kg}$ daily doses predicted for the weight-based and age-based regimens.

Additional file 5: Table S2. Breakdown of the $\mathrm{mg} / \mathrm{kg}$ daily dose for each age in the age-based regimen.

\section{Acknowledgements}

We are very thankful to the Demographic Health Survey of USAID for permission to download their data for Cambodia, Laos, Vietnam and Myanmar. JT is supported by the Wellcome Trust of Great Britain (220211) and RH is supported by the Bill and Melinda Gates foundation (INV-006052).

\section{Authors' contributions}

WRT conceived the idea and oversaw the study with the core team of RH, PP, JT \& MM. MM \& PP conducted the anthropometric analyses, and RH \& JT conducted the pharmacometric analyses. WRT wrote the first draft of the paper with substantial input from RH, PP, JT, MM \& NJW. AD, ARC, AT, DM, FN, FS, JL, KP, LD, LvS, MD, MayM, NHT, NK, PB, RF, RL, RT, SC, SK, SM, SN, STK, TNN, TP, and TTH provided raw data. AT, DM, PB, AR, STK critically reviewed the paper. All other co-authors have seen the final draft of the paper. All authors read and approved the final manuscript.

\section{Funding}

This work was partly supported by a Wellcome Innovator award (WTiTP-2018/001), but the Wellcome Trust was not involved in any aspect of this study.

\section{Availability of data and materials}

Selected data generated and analysed during this study are included in this published article and its supplementary information files. Requests for additional data can be made in the first instance to the corresponding author whose institution has a data access committee that considers requests for data.

\section{Declarations}

Ethics approval and consent to participate

Ethics approval was waived by the Oxford Tropical Ethics committee for this data mining exercise.

\section{Consent for publication}

Not applicable.

\section{Competing interests}

All authors declare that they have no competing interests. Philippe Buchy is currently an employee of GSK Vaccines in Singapore but his work is unrelated to this work.

\section{Author details}

${ }^{1}$ Mahidol Oxford Tropical Medicine Research Unit, Faculty of Tropical Medicine, Mahidol University, 420/60 Rajvithi Road, Bangkok 10400, Thailand. ${ }^{2}$ Centre for Tropical Medicine and Global Health, Nuffield Department of Medicine, University of Oxford, Oxford, UK. ${ }^{3}$ Oxford University Clinical Research Unit, Wellcome Trust Major Oversea Programme, Ho Chi Minh City, Vietnam. ${ }^{4}$ Institut Pasteur du Cambodge, 5 Monivong Boulevard, Phnom Penh 12201, Cambodia. ${ }^{5}$ Department of Global Health, Amsterdam University Medical Center, Amsterdam, The Netherlands. ${ }^{6}$ Shoklo Malaria Research Unit, Mae Sot, Thailand. ${ }^{7}$ Aix-Marseille Université, IRD, INSERM, SESSTIM, Marseille, France. ${ }^{8}$ Myanmar Oxford Clinical Research Unit, Yangon, Myanmar. ${ }^{9}$ Lao-Oxford-Mahosot Hospital-Wellcome Trust Research Unit, Mahosot Hospital, Vientiane, Lao PDR. ${ }^{10}$ Amsterdam Institute for Global Health \& Development, Amsterdam, The Netherlands. ${ }^{11}$ Institute of Research and Education Development, University of Health Sciences, Vientiane, Lao PDR. ${ }^{12}$ Center for Health and Social Development (HSD), National Institute for Public Health (NIPH) and University Research Co., LLC (URC), Chey Chumneas, Daun Penh, Phnom Penh, Cambodia. ${ }^{13}$ AQUITY Global Inc, 987 Avenel Farm Dr, Potomac, MD 20854, USA. ${ }^{14}$ University Research Co., LLC Washington DC, 7200 Wisconsin Ave, Bethesda, MD 20814, USA. ${ }^{15}$ National Center for Parasitology, Entomology and Malaria Control, Khan Sen Sok, Phnom Penh, Cambodia. ${ }^{16}$ Institute of Public Health, Phnom Penh, Cambodia. ${ }^{17}$ Malaria Consortium, London, UK.

${ }^{18}$ MSF Belgium Cambodia Malaria Program, Khan Chamkarmon, Phnom Penh, Cambodia. ${ }^{19}$ Laboratory of Malaria and Vector Research, National Institute of Allergy and Infectious Diseases, National Institutes of Health, Rockville, MD 20852, USA. ${ }^{20} \mathrm{FHI} 360$ Cambodia Office, Keng Kang III Khan Chamkamon, Phnom Penh, Cambodia. ${ }^{21}$ GSK Vaccines, 23 Rochester Park, Singapore, Singapore. ${ }^{22}$ Unité Génétique du Paludisme Et Résistance, Département Parasites Et Insectes Vecteurs, Institut Pasteur, Paris, France.

Received: 30 March 2021 Accepted: 18 August 2021

Published online: 09 September 2021

\section{References}

1. WHO. Guidelines for the treatment of malaria. 2nd ed. Geneva: World Health Organization; 2010.

2. WHO. Guidelines for the treatment of malaria, 3rd edn. Geneva: World Health Organization; 2015. WHO Guidelines Approved by the Guidelines Review Committee.

3. Vieira M, Matos Lopes TR, Mello A, de Sena LWP, Commons RJ, Vieira JLF. Doses of primaquine administered to children with Plasmodium vivax according to an age-based dose regimen. Pathog Glob Health. 2020;114:388-92.

4. Taylor WRJ, Thriemer K, von Seidlein L, Yuentrakul P, Assawariyathipat T, Assefa A, et al. Short-course primaquine for the radical cure of Plasmodium vivax malaria: a multicentre, randomised, placebo-controlled non-inferiority trial. Lancet. 2019;394:929-38. 
5. Chu CS, Phyo AP, Turner C, Win HH, Poe NP, Yotyingaphiram W, Thinraow $\mathrm{S}$, et al. Chloroquine versus dihydroartemisinin-piperaquine with standard high-dose primaquine given either for 7 days or 14 days in Plasmodium vivax malaria. Clin Infect Dis. 2019;68:1311-9.

6. Schmidt $L H$, Fradkin R, Vaughan D, Rasco J. Radical cure of infections with Plasmodium cynomolgi: a function of total 8-aminoquinoline dose. Am J Trop Med Hyg. 1977;26:1116-28.

7. John GK, Douglas NM, von Seidlein L, Nosten F, Baird JK, White NJ, et al. Primaquine radical cure of Plasmodium vivax: a critical review of the literature. Malar J. 2012;11:280

8. Batchelor HK, Fotaki N, Klein S. Paediatric oral biopharmaceutics: key considerations and current challenges. Adv Drug Deliv Rev. 2014;73:102-26.

9. Goncalves BP, Pett $H$, Tiono AB, Murry D, Sirima SB, Niemi M, et al. Age, weight, and CYP2D6 genotype are major determinants of primaquine pharmacokinetics in African children. Antimicrob Agents Chemother. 2017:61:e02590-e2616.

10. Xu JW, Xu QZ, Liu H, Zeng YR. Malaria treatment-seeking behaviour and related factors of Wa ethnic minority in Myanmar: a cross-sectional study. Malar J. 2012;11:417.

11. Marsh VM, Mutemi WM, Muturi J, Haaland A, Watkins WM, Otieno G, et al. Changing home treatment of childhood fevers by training shop keepers in rural Kenya. Trop Med Int Health. 1999;4:383-9.

12. Kuehne A, Tiffany A, Lasry E, Janssens M, Besse C, Okonta C, et al. Impact and lessons learned from mass drug administrations of malaria chemoprevention during the Ebola outbreak in Monrovia, Liberia, 2014. PLoS ONE. 2016;1 :e0161311.

13. Sutanto I, Tjahjono B, Basri H, Taylor WR, Putri FA, Meilia RA, et al. Randomized, open-label trial of primaquine against vivax malaria relapse in Indonesia. Antimicrob Agents Chemother. 2013;57:1128-35.

14. Nelwan EJ, Ekawati LL, Tjahjono B, Setiabudy R, Sutanto I, Chand K, et al. Randomized trial of primaquine hypnozoitocidal efficacy when administered with artemisinin-combined blood schizontocides for radical cure of Plasmodium vivax in Indonesia. BMC Med. 2015;13:294.

15. Cooper WC, Myatt AV, Hernandez T, Jeffery GM, Coatney GR. Studies in human malaria. XXXI. Comparison of primaquine, isopentaquine, $\mathrm{SN}-3883$, and pamaquine as curative agents against Chesson strain vivax malaria. Am J Trop Med Hyg. 1953;2:949-57.

16. Krudsood S, Tangpukdee N, Wilairatana P, Phophak N, Baird JK, Brittenham $\mathrm{GM}$, et al. High-dose primaquine regimens against relapse of Plasmodium vivax malaria. Am J Trop Med Hyg. 2008;78:736-40.

17. Edgcomb JH, Arnold J, Yount EH Jr, Alving AS, Eichelberger L, Jeffery GM, et al. Primaquine, SN 13272, a new curative agent in vivax malaria; a preliminary report. J Natl Malar Soc. 1950;9:285-92.

18. Betuela I, Bassat Q, Kiniboro B, Robinson L, Rosanas-Urgell A, Stanisic D, et al. Tolerability and safety of primaquine in Papua New Guinean children 1 to 10 years of age. Antimicrob Agents Chemother. 2012;56:2146-9.

19. Douglas NM, Poespoprodjo JR, Patriani D, Malloy MJ, Kenangalem E, Sugiarto $\mathrm{P}$, et al. Unsupervised primaquine for the treatment of Plasmodium vivax malaria relapses in southern Papua: a hospital-based cohort study. PLoS Med. 2017;14:e1002379.

20. Moore BR, Salman S, Benjamin J, Page-Sharp M, Robinson LJ, Waita E, et al. Pharmacokinetic properties of single-dose primaquine in Papua New Guinean children: feasibility of abbreviated high-dose regimens for radical cure of vivax malaria. Antimicrob Agents Chemother. 2014;58:432-9.

21. Bunnag D, Karbwang J, Thanavibul A, Chittamas S, Ratanapongse Y, Chalermrut $\mathrm{K}$, et al. High dose of primaquine in primaquine resistant vivax malaria. Trans R Soc Trop Med Hyg. 1994;88:218-9.

22. Kitchener $\mathrm{S}$, Nasveld $\mathrm{P}$, Bennett $\mathrm{S}$, Torresi J. Adequate primaquine for vivax malaria. J Travel Med. 2005;12:133-5.

23. Llanos-Cuentas A, Lacerda MVG, Hien TT, Velez ID, Namaik-Larp C, Chu CS, et al. Tafenoquine versus primaquine to prevent relapse of Plasmodium vivax malaria. N Engl J Med. 2019;380:229-41.

24. Walsh DS, Eamsila C, Sasiprapha T, Sangkharomya S, Khaewsathien P, Supakalin $P$, et al. Efficacy of monthly tafenoquine for prophylaxis of Plasmodium vivax and multidrug-resistant P. falciparum malaria. J Infect Dis. 2004;190:1456-63.

25. Pasaribu AP, Chokejindachai W, Sirivichayakul C, Tanomsing N, Chavez I, Tjitra E, et al. A randomized comparison of dihydroartemisinin-piperaquine and artesunate-amodiaquine combined with primaquine for radical treatment of vivax malaria in Sumatera, Indonesia. J Infect Dis. 2013:208:1906-13.
26. Bangchang KN, Songsaeng W, Thanavibul A, Choroenlarp P, Karbwang J. Pharmacokinetics of primaquine in G6PD deficient and G6PD normal patients with vivax malaria. Trans R Soc Trop Med Hyg. 1994;88:220-2.

27. Hockwald RS, Arnold J, Clayman CB, Alving AS. Toxicity of primaquine in Negroes. J Am Med Assoc. 1952;149:1568-70.

28. Clayman CB, Arnold J, Hockwald RS, Yount EH Jr, Edgcomb JH, Alving AS. Toxicity of primaquine in Caucasians. J Am Med Assoc. 1952;149:1563-8.

29. Cuong BT, Binh VQ, Dai B, Duy DN, Lovell CM, Rieckmann KH, et al. Does gender, food or grapefruit juice alter the pharmacokinetics of primaquine in healthy subjects? Br J Clin Pharmacol. 2006;61:682-9.

30. Sietsma A, Naughton MA, Harley JD. Methaemoglobin levels in soldiers receiving antimalarial drugs. Med J Aust. 1971;1:473-5.

31. Anstey NM, Hassanali MY, Mlalasi J, Manyenga D, Mwaikambo ED. Elevated levels of methaemoglobin in Tanzanian children with severe and uncomplicated malaria. Trans R Soc Trop Med Hyg. 1996;90:147-51.

32. Beutler E, Duparc S, Group GDW. Glucose-6-phosphate dehydrogenase deficiency and antimalarial drug development. Am J Trop Med Hyg. 2007;77:779-89.

33. Chu CS, Bancone G, Moore KA, Win HH, Thitipanawan N, Po C, et al. Haemolysis in G6PD heterozygous females treated with primaquine for Plasmodium vivax malaria: a nested cohort in a trial of radical curative regimens. PLoS Med. 2017;14:e1002224.

34. Leang R, Khu NH, Mukaka M, Debackere M, Tripura R, Kheang ST, et al. An optimised age-based dosing regimen for single low-dose primaquine for blocking malaria transmission in Cambodia. BMC Med. 2016;14:171.

35. Taylor WR, Naw HK, Maitland K, Williams TN, Kapulu M, D'Alessandro U, et al. Single low-dose primaquine for blocking transmission of Plasmodium falciparum malaria - a proposed model-derived age-based regimen for sub-Saharan Africa. BMC Med. 2018;16:11.

36. Borghi E, de Onis M, Garza C, Van den Broeck J, Frongillo EA, GrummerStrawn L, et al. Construction of the World Health Organization child growth standards: selection of methods for attained growth curves. Stat Med. 2006;25:247-65.

37. Wright EM, Royston P. Simplified estimation of age-specific reference intervals for skewed data. Stat Med. 1997;16:2785-803.

38. Rigby RA, Stasinopoulos DM. Smooth centile curves for skew and kurtotic data modelled using the Box-Cox power exponential distribution. Stat Med. 2004;23:3053-76.

39. Chairat K, Jittamala P, Hanboonkunupakarn B, Pukrittayakamee S, Hanpithakpong W, Blessborn D, et al. Enantiospecific pharmacokinetics and drug-drug interactions of primaquine and blood-stage antimalarial drugs. J Antimicrob Chemother. 2018;73:3102-13.

40. Anderson BJ, Holford NH. Mechanistic basis of using body size and maturation to predict clearance in humans. Drug Metab Pharmacokinet. 2009;24:25-36.

41. Holford NHG, Anderson BJ. Allometric size: The scientific theory and extension to normal fat mass. Eur J Pharm Sci. 2017;109S:S59-64.

42. Bennett JW, Pybus BS, Yadava A, Tosh D, Sousa JC, McCarthy WF, et al. Primaquine failure and cytochrome P-450 2D6 in Plasmodium vivax malaria. N Engl J Med. 2013;369:1381-2.

43. Pybus BS, Marcsisin SR, Jin X, Deye G, Sousa JC, Li Q, et al. The metabolism of primaquine to its active metabolite is dependent on CYP 2D6. Malar J. 2013;12:212.

44. Dorji PW, Tshering G, Na-Bangchang K. CYP2C9, CYP2C19, CYP2D6 and CYP3A5 polymorphisms in South-East and East Asian populations: a systematic review. J Clin Pharm Ther. 2019;44:508-24.

45. Puaprasert K, Chu C, Saralamba N, Day NPJ, Nosten F, White NJ, et al. Real time PCR detection of common CYP2D6 genetic variants and its application in a Karen population study. Malar J. 2018;17:427.

46. StaehliHodel EM, Csajka C, Ariey F, Guidi M, Kabanywanyi AM, Duong $\mathrm{S}$, et al. Effect of single nucleotide polymorphisms in cytochrome P450 isoenzyme and $\mathrm{N}$-acetyltransferase 2 genes on the metabolism of artemisinin-based combination therapies in malaria patients from Cambodia and Tanzania. Antimicrob Agents Chemother. 2013;57:950-8.

47. Germovsek E, Barker Cl, Sharland M, Standing JF. Scaling clearance in paediatric pharmacokinetics: all models are wrong, which are useful? Br J Clin Pharmacol. 2017:83:777-90. 
48. Schwartz E, Regev-Yochay G, Kurnik D. A consideration of primaquine dose adjustment for radical cure of Plasmodium vivax malaria. Am J Trop Med Hyg. 2000;62:393-5.

49. Watson J, Taylor WRJ, Bancone G, Chu CS, Jittamala P, White NJ. Implications of current therapeutic restrictions for primaquine and tafenoquine in the radical cure of vivax malaria. PLoS Negl Trop Dis. 2018;12:e0006440.

50. Khantikul N, Butraporn P, Kim HS, Leemingsawat S, Tempongko MA, Suwonkerd W. Adherence to antimalarial drug therapy among vivax malaria patients in northern Thailand. J Health Popul Nutr. 2009:27:4-13.

51. Grietens KP, Soto V, Erhart A, Ribera JM, Toomer E, Tenorio A, et al. Adherence to 7-day primaquine treatment for the radical cure of $P$. vivax in the Peruvian Amazon. Am J Trop Med Hyg. 2010;82:1017-23.

52. Lee WY, Chae DW, Kim CO, Lee SE, Kwak YG, Yeom JS, et al. Population pharmacokinetics of primaquine in the Korean population. Pharmaceutics. 2021;13:652.

53. Chotsiri P, Denoeud-Ndam L, Baudin E, Guindo O, Diawara H, Attaher O, et al. Severe acute malnutrition results in lower lumefantrine exposure in children treated with artemether-lumefantrine for uncomplicated malaria. Clin Pharmacol Ther. 2019;106:1299-309.

54. Hayes DJ, Banda CG, Chipasula-Teleka A, Terlouw DJ. Modelling the therapeutic dose range of single low dose primaquine to reduce malaria transmission through age-based dosing. BMC Infect Dis. 2017;17:254.

55. Hayes DJ, van Buuren S, ter Kuile FO, Stasinopoulos DM, Rigby RA, Terlouw DJ. Developing regional weight-for-age growth references for malaria-endemic countries to optimize age-based dosing of antimalarials. Bull World Health Organ. 2015;93:74-83.

\section{Publisher's Note}

Springer Nature remains neutral with regard to jurisdictional claims in published maps and institutional affiliations.
Ready to submit your research? Choose BMC and benefit from:

- fast, convenient online submission

- thorough peer review by experienced researchers in your field

- rapid publication on acceptance

- support for research data, including large and complex data types

- gold Open Access which fosters wider collaboration and increased citations

- maximum visibility for your research: over $100 \mathrm{M}$ website views per year

At BMC, research is always in progress.

Learn more biomedcentral.com/submissions 